\title{
TRAZENDO O CONTEXTO PARA O CENTRO DA ANÁLISE SOBRE A ATUAÇÃO DAS POLÍTICAS: um estudo acerca da reforma do Ensino Médio e da BNCC em escolas do Ceará
}

\author{
Brena Kécia Andrade de Oliveira \\ Universidade do Estado do Rio Grande do Norte - UERN, Brasil \\ Meyre-Ester Barbosa de Oliveira \\ Universidade do Estado do Rio Grande do Norte - UERN, Brasil \\ Resumo
}

\begin{abstract}
A Reforma do Ensino Médio (REM), sancionada pela Lei 13.415/2017, e a Base Nacional Comum Curricular (BNCC) se constituem como frutos de uma articulação hegemônica que tem o intuito de fixar sentidos sobre a educação e de normatizar os processos educativos, incluindo a atuação dos professores. Com base no pressuposto de que as políticas não são meramente implementadas, buscase compreender como a REM e a BNCC estão sendo atuadas em duas escolas públicas de ensino médio do Ceará. Para tanto, recorre-se à pesquisa de abordagem qualitativa (GASTALDO, 2013), fazendo uso de um estudo documental, bibliográfico e empírico. Em diálogo com a Teoria da Atuação (Policy Enactment) de Ball, Maguire e Braun (2016), analisam-se, a partir da realização de entrevistas semiestruturadas (LOCKMANN, 2013), os processos de subjetivação docente produzidos pela reforma. Como resultado da pesquisa, destaca-se que a Reforma Educacional no Ceará está em curso mesmo antes da aprovação da REM e da BNCC, consubstanciada por meio de parcerias com empresas privadas e de uma perspectiva gerencialista da gestão, com foco em resultados. A participação ativa dos atores privados na produção de políticas contribui para a institucionalização de novas formas de práticas e culturas organizacionais, acentuando os mecanismos de regulação da docência. Contudo, reitera-se que as políticas são interpretadas de maneiras distintas, uma vez que as orientações e as padronizações globais somente se instituem mediante processos de negociação com demandas contextuais.
\end{abstract}

Palavras-chave: Reforma do Ensino Médio; BNCC; Políticas de Currículo; Teoria da Atuação; Regulação da Docência.

\begin{abstract}
The Reforma do Ensino Médio (REM), sanctioned by Law 13.415/2017 and the Common National Curriculum Base (BNCC) are the result of a hegemonic articulation in order to establish meanings about education and to standardize educational processes, including the role of teachers. Based on the assumption that policies are not merely implemented, the aim is to understand how the REM and the BNCC are operating in two public high schools in Ceará. For this, we resorted to research with a qualitative approach (GASTALDO, 2013), making use of documentary, bibliographic and empirical study. In dialogue with the Theory of Action (Policy Enactment) by Ball, Maguire and Braun (2016), we analyze the processes of teacher subjectivation produced by the reform based on semi-structured interviews (LOCKMANN, 2013). As a result of the research, we point out that the Educational Reform in Ceará is underway even before the approval of REM and BNCC, embodied through partnerships with private companies and a managerial perspective of management with a focus on results. The active participation of private actors in the production of policies contributes to the institutionalization of new forms of organizational practices and culture, accentuating the mechanisms for regulating teaching. However, it is reiterated that policies are interpreted in different ways, since global guidelines and standards are only instituted through negotiation processes with contextual demands.
\end{abstract}

Keywords: Reforma do Ensino Médio; BNCC; Curriculum Policies; Acting Theory; Regulation of Teaching.

ISSN 1645-1384 (online) www.curriculosemfronteiras.org 


\section{Introdução}

O presente texto é parte de uma investigação ${ }^{1}$ realizada em nível de mestrado no Programa de Pós-Graduação em Educação (POSEDUC) da Universidade do Estado do Rio Grande do Norte (UERN), cujos resultados foram apresentados na dissertação intitulada "Política de currículo em cena: o discurso dos professores de sociologia sobre a Reforma do Ensino Médio (Lei 13.415/2017) ${ }^{2}$ ". Na ocasião, analisamos os discursos de professores licenciados em Sociologia e/ou Ciências Sociais, com exercício efetivo em escolas públicas localizadas no Ceará, em relação à Reforma do Ensino Médio (REM), sancionada através da Lei 13.415/2017, e à Base Nacional Comum Curricular (BNCC).

Em face das tentativas de regulação da educação por meio de políticas curriculares normativas e impositivas, consideramos indispensável pesquisarmos a atuação da REM e da BNCC nos contextos escolares, dado que as políticas são construídas em diferentes arenas (MAINARDES, 2015). Elas não são meramente implementadas nesses espaços, mas envolvem processos complexos de tradução, interpretação e negociação, resultando em distintas significações.

Buscamos, então, examinar, em diálogo com a Teoria da Atuação (BALL, MAGUIRE, BRAUN, 2016), os processos de subjetivação ${ }^{3}$ dos docentes diante do horizonte discursivo suscitado pelos dispositivos legais que estabelecem estratégias de regulação do currículo e do trabalho docente, sem perder de vista a articulação entre os planos macrossocial e microssocial. Desse modo, visando operar tanto com as assertivas advogadas mediante as políticas curriculares quanto com as dimensões contextuais das escolas, no que se refere às suas particularidades, focalizamos nos processos de mudanças na cultura escolar e nos modos de ação docente em relação aos sentidos fixados pelos discursos das políticas. Assim, pretendemos não marginalizar os processos que se desenvolvem nas instituições escolares, tampouco opacizar as contingências, mas analisar as disputas discursivas em torno desses dispositivos e sua repercussão na organização e no funcionamento das instituições escolares.

Em razão dos objetivos a que nos propomos e dos procedimentos realizados para a constituição deste estudo, que englobou estudo documental (inclusive, escolar), revisão bibliográfica e entrevista semiestruturada (LOCKMANN, 2013), caracterizamos a pesquisa como de abordagem qualitativa (GASTALDO, 2013), tendo em vista, sobretudo, a intencionalidade da compreensão dos fenômenos socioeducacionais. $\mathrm{Na}$ análise e na interpretação do conjunto de dados, buscamos, em diálogo com Ball, Maguire e Braun (2016), exercitar o entrelaçamento das três dimensões: material, interpretativa e discursiva, uma vez que consideramos que isoladamente nenhuma delas poderá nos propiciar uma compreensão mais ampla sobre a atuação das políticas em contextos específicos.

As escolas participantes da pesquisa localizam-se no Ceará e figuram como integrantes do Projeto Piloto da REM. Não obstante o reconhecimento de que os modos de atuação das escolas em relação às políticas são particulares, o que pode ser entendido em razão das especificidades de cada uma, bem como da atuação ativa dos sujeitos no processo de colocar a política em prática, há também as aproximações entre as instituições escolares, principalmente no que concerne à preocupação com as avaliações educacionais e, 
consequentemente, com os resultados, fato que acaba por gerar efeitos na formação educacional.

Organizamos o texto em três seções, além da introdução e das considerações. $\mathrm{Na}$ primeira, esboçamos uma apresentação da Teoria da Atuação (BALL; MAGUIRE; BRAUN, 2016), em diálogo com Lopes (2016); na segunda, explicitamos as dimensões contextuais das escolas na relação com a REM e a BNCC, para analisarmos a atuação das instituições educacionais frente às políticas, a partir de determinados elementos; por fim, na terceira, destacamos alguns aspectos a respeito da atuação escolar em relação à REM e à BNCC, mediante a interpretação das produções discursivas de professoras que lecionam Sociologia, na perspectiva de compreender os processos de subjetivação e regulação ensejados pelas políticas em apreço. Cumpre realçar que a dinamicidade dos processos de atuação das políticas torna os resultados dos estudos empíricos sempre parciais, não podendo ser tomados como "o ser das coisas". Assim, mais do que assertivas, nutrimos o desejo de ensejar, senão novas, outras problematizações sobre como as políticas são atuadas nas escolas. É a partir dessa perspectiva que empreendemos nossa análise.

\section{Notas sobre a Teoria da Atuação (Policy Enactment)}

Para analisarmos como a REM e a BNCC são atuadas nas escolas de ensino médio, dialogamos com a Teoria da Atuação desenvolvida por Ball, Maguire e Braun (2016), um referencial potente para superarmos o binarismo que por vezes predomina nos estudos sobre políticas, colocando em polos opostos política e prática. Essa teoria focaliza nas formas complexas com as quais as escolas e os seus sujeitos lidam com as questões postas pelas políticas, buscando, assim, empreender o esforço de "transformar a política em um processo tão diverso e repetidamente contestado e/ou sujeito a diferentes ,,interpretações ${ }^{\text {ee }}$ conforme é encenado (colocado em cena, em atuação) (ao invés de implementado)" (BALL; MAGUIRE; BRAUN, 2016, p. 13). A partir disso, a análise recai sobre as influências dos aspectos singulares de cada escola na forma como as políticas se estabelecem em seus cotidianos, atribuindo uma atenção aos contextos, que são compreendidos como espaços que iniciam e tornam ativos os processos relacionados às políticas (BALL; MAGUIRE; BRAUN, 2016).

Nesse sentido, a forma como visualizamos as políticas demandam um diálogo com Lopes (2016), a qual realça a potência da abordagem de Ball e colaboradores, particularmente para o campo do currículo, compreendendo que as políticas são interpretadas de formas distintas nos diferentes contextos em que são atuadas. Para a autora, os estudos coordenados por Ball têm mobilizado o desenvolvimento de investigações voltadas para o campo das políticas curriculares, propiciando conclusões mais amplas, de que as orientações centralizadas vinculadas aos interesses de mercado "só conseguem se institucionalizar porque negociam com outras demandas entendidas como locais e que não necessariamente têm sintonia com interesses político-econômicos dos projetos em pauta" (LOPES, 2016, p. 4). Nesse entendimento, as fixações contidas nos textos políticos "são produzidas por 
discursos pedagógicos e disciplinares e, por sua vez, se dispersam localmente tendo em vista contingências das instituições escolares" (LOPES, 2016, p. 4).

Nessa direção, a "política não é ,feita"e em um ponto no tempo; em nossas escolas é sempre um processo de ,tornar-se ${ }^{e e}$ [...] É analisada e revista, bem como, por vezes, dispensada ou simplesmente esquecida" (BALL; MAGUIRE; BRAUN, 2016, p. 15). Noutros termos, a política depende das dimensões contextuais de cada escola, das possibilidades existentes nesses lugares, das traduções que são feitas a partir do que está posto, ou seja, das peculiaridades, que são únicas para cada instituição educacional.

Desse modo, é compreensível que haja semelhanças e diferenças na maneira como as escolas atuam as políticas curriculares, pois não existe homogeneidade, mas, sim, processos singulares e heterogêneos. Destarte, a busca por padronizações, referente à educação, aparenta ser um equívoco, devido à desconsideração das particularidades e das ações de contestação e recontextualização que podem existir nas instituições escolares.

Defendemos que "a política é o exercício da decisão que nos constitui como sujeitos, e essa decisão é sempre contingente [...] toda a opção política é sempre uma opção num conjunto imprevisto de possibilidades" (LOPES, 2013, p. 20). Nessa perspectiva, não é possível que a REM e a BNCC sejam materializadas conforme as prescrições realizadas pelo Estado, dado que a escola também faz parte do processo político e, nela, os sentidos sobre educação podem ser diferentes do que está hegemonizado.

Para o estudo das políticas curriculares, como a REM e a BNCC, Ball, Maguire e Braun (2016) explicitam a potência de se trabalhar com as dimensões contextuais relativas às escolas. Diante disso, consideram os contextos situados, as culturas profissionais, os contextos materiais e os contextos externos a partir da concepção de que tais dimensões são cíclicas e interdependentes, o que torna necessária a atenção sobre as influências que uma dimensão perpetra na outra.

Os contextos situados referem-se às características interligadas a uma determinada instituição escolar no que tange à história, à localização geográfica e ao estabelecimento das matrículas. As culturas profissionais estão de acordo com as disposições dos sujeitos que compõem a escola, associadas ao ethos, ou seja, aos aspectos culturais e comportamentais de uma coletividade, que, no caso, correspondem ao público profissional. Nessa direção, concordamos com Ball, Maguire e Braun (2016, p. 46), quando afirmam que "atores de políticas estão sempre posicionados; como as políticas são vistas e compreendidas é dependente de "onde figurativa e literalmente estamos".

Dito isso, não é válido falarmos de "culturas profissionais" de modo generalizante sem nos atentarmos para as individualidades. Faz-se necessário considerar que uma determinada política pode inquietar mais intensamente um sujeito ou uma coletividade do que outro(a), a depender das particularidades, que, por vezes, estão articuladas também às subjetividades. Assim, é possível apontarmos:

Os professores oscilam, portanto, entre as dinâmicas criativas e submissas, entre a possibilidade de escapar dos discursos políticos impositivos e aquiescer diante deles. A decisão entre esses caminhos não é apenas pessoal. Depende do contexto 
institucional que recebe a política, no qual eventos e encontros cotidianos são importantes espaços a serem investigados, e dos textos que disseminam a política, na forma legislativa ou nos artefatos institucionais: pôsteres, informativos, planos, material de divulgação (LOPES, 2016, p. 6).

Ademais, é importante averiguar a relação entre as disposições prescritivas e as ações desencadeadas no campo institucional, que envolvem a atuação. As condições objetivas das escolas tendem a estar relacionadas às traduções, produzidas pelos sujeitos da política. Por sua vez, os contextos materiais relacionam-se ao ambiente físico da instituição escolar, que tangencia o aparato tecnológico, estrutural e orçamentário, o qual também pode repercutir na atuação das políticas curriculares, uma vez que estas se vinculam às possibilidades presentes/ausentes nas escolas.

É importante considerar, por exemplo, que, se uma escola não possui recurso financeiro significativo, assim como uma estrutura que favoreça um melhor processo de ensinoaprendizagem, e outra possui, os resultados de desempenho estudantil tenderão a ser diferenciados. Contudo, isso não é estimado quando se discute a performance das escolas frente às políticas avaliativas. Os demarcadores sociais do público estudantil também precisam ser considerados, porém, esse aspecto tem sido comumente negligenciado.

Nesse sentido, quando apontamos os contextos externos, referimo-nos às expectativas remetidas às escolas e às responsabilizações. Elas são intrínsecas às pressões interligadas à performatividade, concebida como "a forma por excelência de governabilidade neoliberal, que abrange a subjetividade, as práticas institucionais, a economia e o governo" (BALL, 2014, p. 66).

Reconhecemos que fatores exógenos às instituições também influenciam na dinâmica do espaço interno. Na presente lógica, é preciso termos em vista que as avaliações implicam a reputação das escolas, repercutindo no recrutamento de estudantes e funcionários (BALL; MAGUIRE; BRAUN, 2016). Dessa maneira, percebemos que as questões apontadas estão estritamente interligadas à escola e influenciam nas ações desencadeadas no campo escolar.

O ideário que se cria sobre uma determinada escola, referente aos contextos externos, pode incidir nas matrículas, fato que se relaciona aos contextos situados. É também por essa razão que nos posicionamos de modo contrário aos enquadramentos das instituições escolares por sujeitos e instituições que desconhecem ou não consideram a pluralidade que as constitui. É com base no conjunto de reflexões que constituem a Teoria da Atuação (BALL; MAGUIRE; BRAUN, 2016) que vamos promover a apresentação das escolas pesquisadas.

\section{Apresentação dos contextos de atuação das políticas}

Nesta seção, buscamos realçar as dimensões contextuais das escolas nas quais se desenvolveu o estudo, compreendendo essas dimensões como fundamentais na atuação da política. Assentimos com Ball (2016) que "a política cria o contexto", mas que igualmente "o contexto precede a política", na medida em que as "políticas são colocadas em ação em 
condições materiais". Nessa acepção, consideramos que, apesar das semelhanças que as escolas apresentam, as dessemelhanças podem incidir em diferentes respostas às políticas propostas. Apresentamos, então, um delineamento das escolas a partir dos dados construídos no percurso da investigação, visando compreender as articulações entres as dinâmicas próprias dos contextos e a atuação das políticas.

As escolas que se constituíram como lócus da nossa pesquisa serão denominadas a partir do processo histórico de sua constituição. Assim, designaremos a instituição escolar vinculada à SEFOR (munícipio de Fortaleza) com o pseudônimo de Escola Reunida. De igual modo, nomearemos a escola situada na CREDE 8 (região do Maciço de Baturité) como Grupo Escolar. Apesar de ambos os espaços educacionais serem integrantes do Projeto Piloto da REM e pertencerem à jurisdição do Ceará, cada uma é detentora de peculiaridades, pois são únicas a partir das dimensões contextuais que as constituem (BALL; MAGUIRE; BRAUN, 2016).

O fato de não termos tido acesso a todos os subsídios solicitados à Escola Reunida interferirá na contextualização que faremos dela, o que diferirá do Grupo Escolar, que disponibilizou o material solicitado. Abordaremos alguns aspectos sobre os seguintes documentos das escolas: a) o Projeto Político-Pedagógico (PPP), com o intuito de conhecermos como o processo educacional está delineado e como se articula com as atuais políticas de currículo; b) a matriz curricular, para visualizar como as áreas de conhecimento/disciplinas estão organizadas, tendo em vista que com a REM e a BNCC houve a diluição de componentes curriculares; e c) o Plano de Flexibilização Curricular (PFC), com o propósito de compreender como está ocorrendo a atuação da REM e da BNCC.

A Escola Reunida é fruto da fusão de escolas isoladas. O nome da instituição homenageia uma personalidade da cidade de Fortaleza, que não será mencionada para não quebrar o anonimato da instituição educacional. A instituição escolar é de ensino regular e está localizada na zona urbana, especificamente em um espaço central da capital cearense. Recebe alunos de mais de 100 bairros da capital e também de munícipios próximos. Conta com aproximadamente 100 funcionários escolares (em torno de 61 docentes) e cerca de 1.500 estudantes matriculados nas três séries do ensino médio, que funcionam no período diurno.

A escola tem como slogan, desde 2009, "Uma Escola de Sucesso". Nesse mesmo direcionamento, explicita-se também no PPP o objetivo de tornar "a escola um ponto de referência educacional para a comunidade fortalezense" (CEARÁ, 2014, s/p), aspecto que torna perceptível a pretensão de elevar o padrão da escola. Asseveramos que isso pode ser reflexo da valorização dada pela Secretaria de Educação (SEDUC) a determinadas performances, que tendem a ser definidoras da qualidade de sujeitos e organizações a partir de práticas de julgamento e avaliação (BALL, 2002), em que os profissionais escolares se tornam vítimas e cúmplices desse sistema.

A gestão do diretor que estava lotado na escola em 2020 iniciou-se em 2009, mediante eleição, e tem destaque no texto do PPP, possibilitando-nos pensar que esse profissional é vislumbrado como uma figura central para o desempenho da instituição. Ao profissional, são atribuídas a ampliação das matrículas, as mudanças estruturais e "a redução da reprovação e evasão escolar, a melhoria dos resultados na avaliação externa" (CEARÁ, 2014, p. s/p). 
Essa publicização das conquistas é incentivada pela performatividade como "uma cultura e modo de regulação que se serve de críticas, comparações e exposições como meios de controle, atrito e mudança" (BALL, 2002, p. 5). Desse modo, "os indivíduos e as organizações farão o que for necessário para se distinguir" (BALL, 2005, p. 549) nessa forma de gerenciamento que está presente educação (GEWIRTZ; BALL, 2011).

Consta ainda, no PPP, que no ano de 2014 a "clientela" tem sido formada majoritariamente por egressos de escolas particulares, "além dos alunos das escolas públicas de bairros mais distantes que escolhem estudar longe de suas casas por acreditar que a Escola [...] é a melhor que as escolas próximas as suas residências" (CEARÁ, 2014, s/p). Nesse trecho, é possível identificar um sentido de competitividade na oferta educacional, para que haja uma distinção da escola frente às demais.

Esse fato é problemático, porque pode vir a excluir sujeitos que não possuem as performances tidas como ideais, assim como fortalecer uma cultura de responsabilização docente pelo processo educacional, a partir de metas e da imposição de comportamentos. Tal responsabilização é denotada em alguns excertos do documento, que conclamam os professores a assumirem uma dada performance: "Precisamos, cada vez mais, ser melhores no que fazemos, pois, os alunos, assim como seus pais, exigem uma escola cada vez melhor. E aquela que não prestar um serviço de qualidade, está fadada ao declínio e ao fechamento" (CEARÁ, 2014, s/p).

Concordamos com Ball (2002), quando afirma que a gestão educacional, pautada na competitividade e influenciada também por instâncias privadas, tem apresentado efeitos perversos na subjetividade dos profissionais escolares, tendo em vista que muda o que fazem e são na relação com os outros (BALL, 2002). É importante mencionarmos ainda que o termo avaliação permeia todo o PPP como algo importante a ser considerado na ação dos profissionais da instituição escolar. Não obstante a valorização da avaliação, o documento igualmente expressa tensões compartilhadas pelos educadores, evidenciando "as angústias de um sistema de avaliação considerado falho, na maioria dos aspectos" (CEARÁ, 2014, p. $\mathrm{s} / \mathrm{p}$ ), bem como a resistência em relação às avaliações internas - "não é este sistema avaliativo que queremos" (CEARÁ, 2014, s/p). O descontentamento gera, posteriormente, o seguinte questionamento: "é possível alterar o modelo de avaliação diante das exigências burocráticas do sistema?" (CEARÁ, 2014, s/p).

Observa-se assim, em alguns trechos do documento, a existência de uma insatisfação acentuada dos profissionais escolares com a forma como estão organizadas as avaliações, tendo em vista que barram suas respectivas autonomias sobre o fazer educativo na escola. A análise do contexto demonstra que as práticas discursivas sobre a educação são diversas e, por vezes, antagônicas, evidenciando que a escola é um espaço de recontextualização do que está posto no âmbito educacional, ao mesmo tempo que nos possibilita ver a ruptura entre o que os professores consideram boas práticas e as imposições de desempenho (BALL, 2005).

Apesar de a REM e a BNCC não serem mencionadas na contextualização acerca dos documentos curriculares (que pode ser devido ao PPP estar desatualizado), a lógica das atuais políticas encontra-se presente nas ações escolares em razão do discurso de enaltecimento dos componentes curriculares de português e matemática, que são valorizados pelas políticas de 
avaliação. Nesse cenário, disciplinas deslegitimadas pela REM, como a sociologia e a filosofia, não conseguem ampliar seu espaço, permanecendo com sua carga horária de uma aula semanal por turma.

Para além da des/valorização de alguns componentes, é importante ressaltar que programas, projetos e outros componentes curriculares adentraram a escola sem estarem ancorados numa ciência de referência, a exemplo do Núcleo de Trabalho, Pesquisa e Práticas Sociais (NTPPS) e da "Formação para Cidadania e Desenvolvimento de Competências Socioemocionais" (PDDT) e o Jovem de Futuro, que são iniciativas do mercado (RÖWER; OLIVEIRA; FREIRE, 2021).

A segunda instituição escolar participante do estudo foi criada em 1953 em forma de grupo escolar e, por isso, a sua denominação para efeito desta pesquisa. A instituição Grupo Escolar oferta ensino regular e Educação de Jovens e Adultos (EJA) e está situada no centro de um município do Maciço de Baturité, em área de fácil e tranquilo acesso. Funciona nos três turnos, estando composta por com 16 turmas, sendo 8 pela manhã, 7 à tarde e 1 à noite. Recebe 557 alunos e possui 62 funcionários, sendo 30 professores com exercício na docência, 23 desses com vínculo temporário e 7 efetivos (estando 5 lotados fora da sala de aula).

Ao lermos o PPP, que está organizado por seções, identificamos que no Grupo Escolar o desafio educacional consiste em "ofertar a educação a comunidade heterogênea que busca na escola conhecimento para garantir melhores condições de vida, econômica, social e cultural, sendo referência em qualidade, contribuindo para construção de um mundo melhor" (CEARÁ, 2020, s/p). Fica explícito o reconhecimento de que a comunidade estudantil é formada por sujeitos singulares, sendo exposta a pretensão de possibilitar uma educação de qualidade, que possa repercutir positivamente na vida do alunado e na sociedade.

É expresso, por conseguinte, que o diretor escolar, em acordo com as políticas educacionais do Ceará, "defende uma visão de Homem, Sociedade, Educação, Currículo, Conhecimento, Ensino-Aprendizagem e Avaliação voltada para o bem comum, para a propagação da paz e para a formação de sujeitos ecologicamente responsáveis pelo bem comum" (CEARÁ, 2020, s/p). Identificamos também, através do PPP, o "intuito de garantir a permanência e o sucesso dos alunos, elevando os indicadores de aprendizagem, envolvendo a comunidade de forma democrática, participativa, inclusiva e cidadã na construção de um mundo melhor" (CEARÁ, 2020, s/p).

Em face da amplitude de propósitos educativos na escola esboçados no documento, é perceptível um hibridismo de concepções educacionais com traços distintos (LOPES; MACEDO, 2011), mas que estão em cena no campo curricular como espaço agregador de diferentes demandas. Esse fato se articula com os elementos constituintes das políticas curriculares que trazem princípios tanto de uma educação mais ampla quanto instrumental, dando ênfase às demandas que lhes são prioritárias.

Sobre as intencionalidades educacionais e hibridismos que constituem o texto, destacase que "o processo [...] deve contemplar um tipo de ensino e aprendizagem de forma dialógica que ultrapasse o simples repasse e reprodução de saberes cristalizados" (CEARÁ, 2020, s/p) e que "o educando torne-se crítico e que exerça a sua cidadania, refletindo sobre as questões sociais e buscando alternativas de superação da realidade" (CEARÁ, 2020, s/p). Contudo, 
em seguida, expressa que a educação "é o meio de inserir o aluno no mercado de trabalho, bem como torná-lo apto as demandas postas pelo capitalismo, além de ser o cerne da transformação dessa realidade" (CEARÁ, 2020, s/p).

A análise do PPP nos permite refletir sobre as ambiguidades, próprias do processo de produção dos textos políticos. No caso exemplificado, observamos a ambiguidade de demandas em relação à formação dos estudantes mediante a diversidade de sentidos educacionais. Tal fato tende a ocorrer devido à articulação de demandas diversas e, por vezes, antagônicas na produção dos documentos. Num momento, faz-se uma crítica ao sistema vigente e, em outro, endossa-se a perspectiva de adaptação ao mercado. Tais ambivalências geram implicações sobre as propostas educacionais e também favorecem uma heterogeneidade de leituras nos diferentes contextos que entram em contato, podendo resultar em recontextualizações.

Por meio do PPP, são apresentados aspectos críticos relacionados à escola que precisam ser enfrentados. Destacam-se a evasão no turno vespertino, a baixa autoestima dos alunos, o baixo desempenho de alguns alunos em diversas disciplinas, a indisciplina e a rotatividade de professores por causa do grande número de contratos temporários. Esse último aspecto é uma problemática já sinalizada por Venco (2020), visto que, em 2018, verificou-se um percentual de $40 \%$ de professores não efetivos lecionando nas escolas do Brasil. No caso do Ceará, a precarização docente, compreendida pelo vínculo instável, chegou a $61 \%$ em 2018 , a partir de oscilações existentes desde 2011 (VENCO, 2020), aspecto que precisa ser alvo de intervenção.

Ao analisarmos a matriz curricular do Grupo Escolar, notamos que segue o padrão de valorização de algumas disciplinas em detrimento de outras, em termos de carga horária, como português e matemática. Por sua vez, a disciplina de arte é ofertada somente no $1^{\circ}$ ano do ensino médio, com apenas uma aula semanal. No tocante à sociologia e à filosofia, são ministradas nas três séries, com apenas uma aula semanal por turma. Na parte diversificada, que diz respeito à flexibilização curricular, aparece o componente Formação para a Cidadania, com uma aula semanal nos $2^{\circ}$ e $3^{\circ}$ anos, e o NTPPS, com 5 aulas semanais no $1^{\circ}$ ano do ensino médio.

No Plano de Ação da escola, no eixo em que são agrupadas as metas e ações a serem cumpridas, o Sistema Permanente de Avaliação da Educação Básica do Ceará (SPAECE) é mencionado, juntamente com o Exame Nacional do Ensino Médio (ENEM), na perspectiva de motivar a participação dos alunos e, assim, cumprir a meta de elevar o desempenho dos estudantes nas avaliações internas e externas em $10 \%$.

Existe uma visível preocupação em sanar problemáticas da escola através de ações interventivas, conforme observado no PPP da instituição, o que engloba a divulgação mais efetiva dos bons resultados dos alunos nas avaliações externas e nas olimpíadas mediante criação de outdoor com fotos dos estudantes de desempenho significativo, formação de grupos de estudo e mapeamento dos alunos com excesso de indisciplina.

A escola tem criado um número de programas e projetos ${ }^{4}$ considerável, os quais podem ser compreendidos como micropolíticas, ou seja, processos criados na instituição escolar. Tal fato demonstra a não limitação das instituições escolares em face das políticas já instituídas 
e elaboradas no âmbito do estado (BALL; MAGUIRE; BRAUN, 2016). Dentre as intencionalidades dos programas e projetos constituídos pelas escolas, está o estabelecimento de intervenção nos pontos considerados negativos da escola, como a questão dos resultados nas avaliações.

Nessa direção, observa-se uma ênfase em programas e projetos que favorecem o desempenho dos alunos em exames externos e também no ENEM, embora constem outros propósitos formativos. Esse aspecto se configura como um hibridismo (LOPES; MACEDO, 2011) acerca dos sentidos que direcionam as ações desempenhadas na escola. Percebemos, assim, tanto a criação de micropolíticas, com o objetivo de atender as necessidades específicas da instituição educacional, quanto a sua elaboração, com o intuito de contemplar as demandas apresentadas pelos "dirigentes" da educação.

Por sua vez, a "flexibilização curricular" descrita no PFC está associada às demandas apresentadas pela REM, objetivando reconfigurar essa etapa de escolarização. Na esteira, as ações de flexibilização curricular englobam "ciências na natureza", "linguagens e códigos" e "todas as áreas" e fazem referência, dentre outros elementos, ao projeto Recriando Rotas (circuito de gestão), às oficinas interdisciplinares (circuito de gestão), à modernização de laboratórios e à ampliação do acervo da sala de multimeios. Embora essa última atividade esteja descrita para "todas as áreas", a aquisição do acervo está direcionada principalmente para autores da língua portuguesa. A ênfase, nesse caso, é dada para as disciplinas de português e matemática, com vistas ao aumento de proficiência nas áreas que também são valorizadas no âmbito global, o que nos permite perceber o empréstimo de ideias (BALL, 2001) e a hegemonização de sentidos educacionais que favorecem o ensino de determinados conteúdos em detrimento de outros.

No projeto consta a descrição de ações relativas à "Execução dos recursos recebidos via PDDE novo ensino médio" para a $1^{\mathrm{a}}, 2^{\mathrm{a}}$ e $3^{\mathrm{a}}$ etapas, em que se apresentam: a ação, os itens, a finalidade e o valor. As ações compreendem formação dos professores, protagonismo juvenil, projeto de vida, modernização da LEI e formação continuada de professores com a finalidade de ampliar o conhecimento sobre o novo ensino médio, a formação acerca da BNCC e a produção de material pedagógico. Os itens são os objetos que a escola deve adquirir, como projetor, mesa, armários e impressora, bem como ações para estruturar ambientes para realização de atividades, como o projeto de vida e a organização da feira NTPPS, dentre outras.

Algumas atividades carregam a marca do "circuito de gestão", que é um método que consolida a Gestão Escolar para Resultados de Aprendizagem (GEPR), mediante a realização de 4 etapas (planejamento, execução do plano de ação, monitoramento e avaliação de resultados e correção de rotas). O método é inspirado no PDCA (Plan - Do - Check - Act), que em português significa planejar, executar, checar e atuar/ajustar. Os agentes de implantação são o gestor escolar e o profissional de Apoio ao Circuito de Gestão (ACG). Cabe ao diretor liderar os processos dentro da escola, enquanto o profissional de ACG tem a função de orientar, acompanhar e monitorar a implementação do Circuito de Gestão (INSTITUTO UNIBANCO, s/a). Essa ação acontece a partir do programa Jovem de Futuro, que é uma iniciativa do Unibanco com a SEDUC. 
A influência do setor privado na escola pública é observada na indicação de metas e direcionamento da atuação do diretor escolar como sendo o gerenciador de uma empresa. Além disso, há o estímulo de performances que são típicas do sistema produtivo, na busca de incutir a competitividade e a produtividade nos agentes que fazem o processo curricular nas escolas. Ademais, a ideia de o estudante ser protagonista do seu próprio processo educacional, calcada na construção de um projeto de vida, a partir de uma perspectiva empreendedora e de competências socioemocionais, conflui para uma responsabilização individual dos resultados de suas respectivas ações, ao mesmo tempo que desresponsabiliza o Estado de assisti-lo e coordena a uma maior adaptação da formação às demandas do mercado.

No entanto, mesmo com a presença desses aspectos que visibilizam a influência dos interesses de mercado na educação, é preciso também considerar as críticas dos profissionais escolares em relação a quesitos que não são concebidos enquanto problemáticos pelas políticas curriculares, como é o caso da rotatividade dos professores. Contudo, essa é uma questão que repercute na atuação das políticas, uma vez que seus efeitos trazem implicações para a docência e o processo educacional, conforme é evidenciado no PPP escolar. São inclusive essas ambiguidades postas sobre o cenário educacional que continuaremos a explorar adiante.

\section{A atuação das políticas no contexto escolar}

Com o objetivo de compreender a atuação das escolas em relação à REM e à BNCC, entrevistamos duas docentes que ministram a disciplina de sociologia em escolas do Ceará. Para preservar o anonimato de ambos e em conformidade com as questões de ética na pesquisa, as nominamos de CR (pertencente ao Grupo Escolar) e SF (pertencente à Escola Reunida), em referência aos órgãos ${ }^{5}$ a que estão vinculados. Também usamos o gênero feminino por uma questão de concordância com os pseudônimos usados, independentemente do gênero dos sujeitos.

Asseveramos que foi de suma importância ouvir as professoras sobre a REM e a BNCC, visto que as políticas não possuem um sentido fechado, ou seja, podem ser compreendidas de variados modos pelos sujeitos escolares, que, por sua vez, recorrem a instrumentos particulares para produzir leitura sobre aquilo que os cerca (BALL; MAGUIRE; BRAUN, 2016), fato que não permite o encerramento das políticas no âmbito legislativo.

Nesse sentido, constatamos que CR acompanhou as discussões acerca da REM através de formações e planejamentos. No tocante à formação, CR (2020) confidenciou que a formadora (coordenadora pedagógica da escola) gerou a impressão de que a gestão da escola "nem sabe o destino" da política e que o material bibliográfico usado no processo formativo "ficou mais ou menos entendido". A esse respeito, consideramos que a incompreensão faz parte do processo de atuação singular da política (BALL; MAGUIRE; BRAUN, 2016), na medida em que existem muitas possibilidades de leitura diante dos textos que são direcionados aos sujeitos escolares pelo caráter confuso e híbrido que possuem. 
Para CR (2020), na REM, “a ideia principal é tirar as Ciências Humanas”, justificando que "o próprio governo federal fala que o ideal é investir nas Ciências Exatas que são as ciências do desenvolvimento, que traz o progresso e que as humanas são ideológicas”. Essa tradução realizada pela docente acerca da política curricular revela que recorreu a uma análise sobre o panorama social para a elaboração de sentido a respeito da REM. Isso demonstra concomitantemente que essa política como um discurso é "apenas um particular [...] que se universalizou e, para tal, esconde as marcas da sua contingência” (LOPES, 2016, p. 8) em relação aos demais contextos educacionais.

SF também teve acesso às discussões sobre a REM e a BNCC, majoritariamente no âmbito escolar, através de formações e planejamentos, em que a BNCC foi apresentada com a mediação de um funcionário da SEDUC/CE, diferentemente do que ocorreu na escola que CR (2020) leciona. Tal fato nos possibilita refletir que nem todos os atores de políticas são das escolas (BALL; MAGUIRE; BRAUN, 2016), em face das forças exteriores que tentam influenciar na atuação da política no âmbito escolar, a fim de direcionar uma formação construída discursivamente como ideal.

É comum que a apresentação das políticas para os sujeitos escolares seja feita por outros sujeitos. Isso faz com que as significações produzidas pelos "apresentadores" possam se tornar hegemônicas naquele espaço por ser o "conhecedor(a)", que pode se posicionar como um defensor das políticas que estão em cena (BALL; MAGUIRE; BRAUN, 2016).

Como a SEDUC/CE realizou o processo de mediação das políticas advindas do MEC junto à Escola Reunida na qual SF trabalha, é possível que a tradução feita pelos sujeitos acerca da REM e da BNCC esteja fortemente de acordo com os sentidos tecidos pela SEDUC/CE sobre as políticas, embora possam existir reconstruções de sentidos (SANTOS; SILVA, 2017), dado que "a política não remete apenas à produção, de um centro, de uma estabilidade, um freio na flutuação de sentidos, é também produção do diferir, do descentramento, da instabilidade" (LOPES, 2016, p. 10). Por essa razão, é importante que as investiguemos em sua trajetória, ou seja, na relação com as escolas.

Nesse cenário, explicitamos que SF (2020) considera a REM como necessária e urgente, mas pondera que "tem que partir do chão da escola, tem que ser feita [...] a partir de quem está dentro, de quem tem a vivência, que seriam professores, alunos, gestão. Não a forma como está sendo implantada". A professora expressa uma crítica em torno da definição do Estado sobre como deve ocorrer o processo educacional.

Ao ser questionada a respeito do teor dessa REM em particular, SF (2020) salienta que a "reforma na verdade ela não tem uma certa consistência porque não aparenta segurança por quem está produzindo", apontando assim as fragilidades da política, como a questão dos itinerários formativos e a ausência de uma "orientação clara".

Em direção contrária à ideia de ausência de "orientação clara", entendemos que existe uma série de aportes que podem ser compreendidos como orientadores da REM e da BNCC, que são advindos inclusive de instâncias que buscam influenciar fortemente a materialização das políticas através da produção e disponibilização de recursos, como guias que intentam conduzir a ação dos sujeitos escolares. 
Notamos nesses instrumentos prescritivos uma tentativa de estreitar as respostas criativas (BALL; MAGUIRE; BRAUN, 2016) dos membros das escolas e de gerar uma conexão dos sujeitos à política. Lopes e Macedo (2011) ressaltam que a ideia da política como uma direção para a prática tem sido presente nos estudos desde a década de 1970, havendo assim uma supremacia de pesquisas centradas no âmbito do Estado, que concebe a política de modo hierarquizado, "como produção que emana de um poder central [...] para posterior implementação" (OLIVEIRA, 2016, p. 44). Acreditamos que essa via de análise estadocêntrica tende a desconsiderar os processos micropolíticos de recontextualização das políticas.

Na continuidade do diálogo sobre as políticas, SF (2020) infere que "na implantação da BNCC da REM o estado do Ceará não vai ser vanguarda, vai aguardar algumas orientações mais claras para a gente poder dar os passos". Observamos, assim, certa ambiguidade no posicionamento de SF (2020), uma vez que em outro momento expressou descontentamento pelo fato de a REM ter sido imposta e que, ao contrário disso, teria que "partir do chão da escola".

Contudo, seu posicionamento expressa a dependência em relação à atuação das políticas a partir das orientações do MEC e da SEDUC/CE, convergindo com a ideia de a política ser elaborada fora da escola e operacionalizada nesse espaço, de modo linear, perspectiva com a qual não concordamos. Consideramos que na Escola Reunida os "passos" já estão sendo dados através de atuações específicas. Ademais, o estado do CE também está agindo (num processo de tradução) em relação à REM e à $\mathrm{BNCC}$, tendo em vista a construção do Documento Curricular Referencial do Ceará (DCRC).

Ao analisarmos a versão preliminar desse texto, percebemos que, mesmo quando a REM opera para garantir estabilidade, "cria as possibilidades de romper com o que se apresenta estável” (LOPES, 2016, p. 10), ao oportunizar, para os sistemas de ensino, a realização de suas construções curriculares. Então, mesmo com os cerceamentos da política, o currículo produzido no contexto educacional cearense traz garantias que a REM desestabiliza, como a oferta obrigatória de todas as disciplinas no ensino médio.

Além disso, a REM não demonstra ser uma política tão influente em determinados contextos, considerando que, de acordo com CR (2020), as discussões sobre a BNCC, documento que a legitima, têm ocorrido de forma pontual na escola, semanalmente (durante quase 8 meses). CR (2020) afirma, ainda, que não esteve presente em todas as formações em decorrência de outro compromisso profissional, no qual atua como preceptora de sociologia do Programa Residência Pedagógica ${ }^{6}$. Em sua fala, tece críticas ao MEC, pelo que julga como intenção de "ficar dono total do Plano Nacional do Livro Didático e fazer a história da visão neoliberal". Sua análise trata da associação do MEC com agentes privados em torno da centralização da política curricular (MACEDO, 2014), o que logicamente fortalece o sistema neoliberal no âmbito da educação pública.

Questionamos as entrevistadas se as políticas supracitadas têm interferido no cotidiano das escolas. CR (2020) revela que "estamos assustados e perdidos", ao se referir à coletividade da instituição educacional. Isso possibilita a compreensão de que "colocar as 
políticas em prática é [...] um processo complexo" (BALL; MAGUIRE; BRAUN, 2016, p. 21), que pode causar estranhamento e aflição nos contextos que entram em contato.

A docente ressalta que "a escola é democrática [...] e os professores não comungam com as propostas do atual governo [...]", afirmando: "[...] somos uma escola realmente de resistência a essas questões que estão postas para gente". Suas falas nos possibilitam interpretar que a escola tem uma postura contrária às políticas, o que pode gerar um processo de recontextualização que reconfigura as intencionalidades da REM e da BNCC.

Nessa perspectiva de movimentação em torno das políticas, CR (2020) salienta que está matriculada em um curso on-line obrigatório para a área de Ciências Humanas e Sociais Aplicadas e acredita que deva ser uma proposta encaminhada pela CREDE 8. Embora não soubesse ainda o teor do curso, uma vez que não havia iniciado as aulas, tinha a informação de que se tratava da BNCC. Essa formação pode se configurar como mais um instrumento de influência para as ações dos sujeitos escolares, posto que os "momentos formativos" são dotados de intencionalidades, com vistas a direcionar uma determinada lógica de reflexão e ação.

Por sua vez, SF (2020) analisa que as políticas irão "modificar o cotidiano da escola", assinalando que no atual momento está havendo "as discussões nos planejamentos [...]", porém considera que até o momento "[...] não mudou o cotidiano, a rotina da escola ainda não". Contudo, percebemos que as ações decorridas no âmbito escolar demonstram que as modificações já estão em curso, havendo um processo de atuação das políticas (BALL; MAGUIRE; BRAUN, 2016), embora por vezes não haja o reconhecimento desses elementos como mudança. A utilização do termo "ainda não" pela docente para se referir às mudanças a partir das políticas significa uma expectativa de que algo mais concreto (com base na sua reflexão) está por vir.

No sentido de atuação em relação às políticas, SF (2020) relata que estão ocorrendo na escola reflexões e discussões sobre os itinerários formativos do Novo Ensino Médio, embora não se tenha segurança acerca da implantação. A esse respeito, afirma:

A gente já sentou para ver possibilidades e simulações de como isso pode ser feito. Estamos vendo algumas experiências pontuais de algumas escolas que estão acontecendo no Estado e tentando entender e ver como se sistematizaria nessa escola. Estamos falando de uma escola de mais de 1500 alunos, de 20 turmas por turno. São 20 turmas pela manhã e 20 turmas à tarde, então tudo é muito grandioso, algumas experiências podem ser replicadas, outras não (SF, 2020).

A partir dessa análise, SF (2020) considera a necessidade de uma recontextualização da política com base no contexto local, o que é compreensível, porque "políticas de tamanho único encalham ao baterem nas rochas da vida real" (BALL; MAGUIRE; BRAUN, 2016 p. 206), ou seja, em escolas com dimensões contextuais particulares. Por conseguinte, a professora destaca que os sujeitos da escola estão "estudando como vai ser implantado, porque não há essa orientação", o que indica certa expectativa de um direcionamento mais prescritivo. 
SF (2020) evidencia ainda que, em torno da atuação das políticas, conforme sua percepção, há, na escola, professores dispostos a mudar, ou seja, a atender as demandas da Reforma do Ensino Médio e da BNCC, enquanto outros não estão disponíveis. Essa ponderação traz à tona a complexidade do processo político, ao expor a existência de tensões profissionais numa mesma instituição, tendo em vista as posições diferentes dos sujeitos em relação às políticas.

A professora salienta que, "enquanto tem um grupo que deseja mais, que se preocupa em como operacionalizar, existe outro grupo, embora bem menor, que não vê a necessidade ou acha que é mais alguma coisa que não vai dar em nada" (SF, 2020). A política engloba lutas e contestações nos diferentes contextos, inclusive no âmbito da prática, a partir de processos de tradução singulares (BALL; MAGUIRE; BRAUN, 2016) desempenhados pelos sujeitos da política.

Na escola onde SF (2020) trabalha, os profissionais que são favoráveis às políticas acreditam que é preciso haver uma reforma educacional e que, para tanto, torna-se necessário o desempenho de ações no âmbito escolar. Porém, para os que demonstram apatia em face das políticas, não é necessário que haja iniciativas a esse respeito. Essa diferença de postura pode se dar devido ao fato de que "as escolas são constituídas [...] de diferentes gerações, de professores com diferentes disposições em relação ao ensino e à aprendizagem, fixados dentro de diferentes ondas de inovação e de mudança" (BALL; MAGUIRE; BRAUN, 2016, p. 18).

SF (2020) destaca, nessa dinâmica, que "tem alguns projetos aqui na escola que a gente observa a possibilidade de fazer esse trabalho mais amplo, mais dinâmico com mais significado para os alunos, interdisciplinar”. Essa necessidade de promover uma educação com mais significado para os estudantes também é anunciada nos discursos que operam a favor da flexibilidade do ensino médio e dos itinerários formativos, conforme as propagações do MEC.

CR (2020) não pontua nenhum conflito entre os docentes da escola em razão da REM e da BNCC. Contudo, assinala que a posição dos professores em relação às políticas é de resistência, assim como considera que a Universidade da Integração Internacional da Lusofonia Afro-Brasileira (UNILAB) os fortalece bastante na reflexão sobre o papel e a importância que possuem como docentes, citando, nesse caso, os eventos acadêmicos que a Instituição de Ensino Superior (IES) realiza como espaços de formação acadêmica e política.

Pontuamos que o curso de Licenciatura em Sociologia da Unilab, área na qual CR (2020) é formada, tem uma forte aproximação com as escolas da região do Maciço de Baturité. Formam, assim, parcerias na realização de ações, como a Semana de Sociologia da Escola de Ensino Médio Doutor Brunilo Jacó (primeira edição em 2017) e a Semana de Sociologia das Escolas do Maciço de Baturité ${ }^{7}$ (primeira edição em 2020).

Além disso, sucedem na universidade também atividades abertas aos professores da educação básica, como a II Semana de Sociologia na Unilab ${ }^{8}$, que abordou o tema "Sociologia na escola: conhecimentos, tensões e mobilizações políticas" e debateu acerca do movimento "escola sem partido", da REM e da BNCC. Consideramos que essa articulação da escola com a universidade pode estar contribuindo para a reflexão sobre o poder como 
algo descentralizado do Estado e presente também nas escolas, como espaços aos quais as políticas de currículo estão direcionadas.

Ademais, é importante ressaltar que existem licenciandos em sociologia nas escolas, por meio de programas como a Residência Pedagógica e o Estágio Supervisionado em Sociologia, que são mecanismos de aproximação entre universidade e escola e também de influência nos sentidos educacionais. Desse modo, é possível visualizarmos que o Estado atua como um agregador dos interesses privados na educação, não sendo a única instituição de influência nas escolas.

Por isso, não trabalhamos com a perspectiva de que a REM e a BNCC são linearmente implementadas nas escolas, mas atuadas a partir de variadas circunstâncias (BALL; MAGUIRE; BRAUN, 2016). As políticas se estabelecem de forma processual, uma vez que envolvem disputas e negociações contínuas em diversas arenas, algo que não permite o controle do Estado em relação à forma como serão efetivadas. É justamente pela imprevisibilidade e contingência acerca das políticas de currículo que nos dissociamos de perspectivas deterministas a respeito da escola e do social.

\section{Considerações}

A REM e a BNCC trazem assertivas comuns para as escolas brasileiras, com o intuito de promover uma educação utilitarista para os jovens, de modo a torná-los aptos ao mercado de trabalho e instrumentalizá-los para as avaliações nacionais em larga escala. No entanto, como textos, as políticas estão suscetíveis a variadas leituras, que podem vir a ser dissonantes e conflitantes aos interesses daqueles que as instituíram.

Esses aspectos foram percebidos no estudo que realizamos sobre a atuação da REM e da BNCC nas escolas cearenses. Embora ambas as instituições escolares estejam dedicadas a agregar conquistas que elevem seu respectivo status social e seus índices nas avaliações, a forma como estão operando as políticas se mostra específica.

Apesar de não termos visualizado no PPP da Escola Reunida e do Grupo Escolar menções à REM e à BNCC, as lógicas de mercado, performatividade e ênfase nas avaliações que permeiam as políticas de currículo estão presentes, ainda que em intensidades diferentes. Observou-se, igualmente, que parte considerável das micropolíticas criadas nas instituições educacionais em apreço revela uma preocupação com os índices, fato que demonstra a influência do contexto externo nas escolas.

Percebemos em ambas as escolas uma flexibilização do currículo, configurada na inserção de disciplinas não tradicionais que passam, inclusive, a ocupar uma carga horária significativa. A própria coordenadora do Grupo Escolar expressou que componentes curriculares como o NTPPS e a Formação para a Cidadania, que são ofertados mediante parcerias privadas estabelecidas antes das políticas em pauta, terminam por contribuir para atender as demandas suscitadas pela REM. Enquanto isso, nessa mesma escola, a disciplina de artes passou a ser ofertada unicamente no $1^{\circ}$ ano do ensino médio, aspecto que compromete a formação mais ampla do alunado e a torna mais técnica. 
Além disso, ao analisarmos o PFC do Grupo Escolar, única instituição educacional que nos disponibilizou esse documento, percebemos que há ações que se coadunam com os sentidos educacionais valorizados pela REM e pela BNCC, como a ênfase na potencialização do ensino de português e matemática e a oferta de formação docente sobre as políticas. Tal aspecto evidencia o entrelaçamento entre as políticas e a circulação de sentidos que se alinham aos interesses do mercado e a perspectivas globais.

Por sua vez, a Escola Reunida se destaca na busca por ser uma instituição de renome social, conforme apresentado no seu slogan: "Uma escola de sucesso". Esse tipo de identidade é objetivado majoritariamente por escolas privadas, que intencionam conquistar uma visibilidade no mercado educacional por meio de determinados resultados. Contudo, esse sentido de competitividade também está presente na rede estadual cearense, que valoriza as políticas de avaliação e as utiliza para gerar recompensas para as escolas que possuem um desempenho considerado significativo.

$\mathrm{Na}$ Escola Reunida, também identificamos que existem ações sendo concretizadas em relação à adequação do ensino à REM, como a realização de pesquisa sobre os interesses dos estudantes acerca dos itinerários formativos e a busca por realização de trabalhos que envolvam diferentes disciplinas, de modo a superar a "fragmentação" criticada pela política. Existe, ainda, uma preocupação em como operacionalizar a REM, conforme é perceptível na fala da professora SF. Não obstante, no decorrer da sua narrativa, a docente evidenciou conflitos entre os professores quanto às políticas, justamente devido a posicionamentos desfavoráveis à REM por parte de alguns, o que evidencia a disputa de sentidos como inerente ao processo de atuar as políticas.

Por sua vez, o Grupo Escolar, a partir dos discursos de CR, está mais distante das demandas apresentadas pela REM e pela BNCC. A docente nos possibilita, inclusive, perceber que existe uma resistência na escola no que concerne às políticas, uma vez que compreende haver discordância por parte dos sujeitos escolares quanto aos elementos postos pelo texto da política curricular. Nessa perspectiva, CR demonstra ser crítica à REM e à BNCC, citando a Unilab como instituição que tem influenciado um sentido de educação dissonante do que advogam as políticas. Ao contrário do posicionamento de CR sobre a REM e a BNCC, a professora SF evidencia um dado entusiasmo e proximidade com as políticas, mesmo que com ponderações ambíguas.

Ademais, é possível inferir, com base na realização da presente pesquisa, que alguns dos sentidos presentes na Reforma Educacional e na BNCC encontram-se também nas escolas pesquisadas, mesmo antes de sua aprovação. Esse fato revela a existência de um contexto multifacetado, que influencia a produção de políticas e conduz ao processo de hegemonização de determinados sentidos e respostas para os problemas educacionais, dentre os quais se destacam a valorização das políticas de avaliação, inclusive mediante o SPAECE, e a relação estabelecida com a área de negócios, que tem repercutido na forma como se estabelece o currículo. Todavia, asseveramos que as problemáticas da educação podem ser agravadas com as atuais políticas, que disponibilizam até mesmo um orçamento específico para fins de materialização dos comandos. 
Cumpre realçar que, embora haja mecanismos com o intuito de estabelecer e normatizar padrões de funcionamento homogêneos, cada um dos contextos produz leituras distintas a partir de suas singularidades, o que permite articulações diferenciadas. Nessa acepção, não podemos afirmar que uma pesquisa abarca de modo complexo e abrangente todos os efeitos da atuação de uma política em dado contexto, uma vez que se soma a esta um conjunto de outras políticas e de fatores próprios da dinâmica das instituições nas quais a política é atuada.

Ademais, como o vir a ser das políticas não pode ser controlado e não há nenhuma garantia sobre o que vá ocorrer na sociedade, justamente pelo fato de o social ser marcado por jogos de interesses e disputas, é indispensável que continuemos a nos debruçar sobre a atuação da REM e da BNCC nas escolas, visto que tais políticas não são meramente materializadas. O processo político é complexo e multifacetado, de modo que, por essa razão, precisamos recorrer a uma análise mais elaborada, para não recairmos em assertivas simplistas e exatas, que não correspondem à dinamicidade do contexto escolar.

\section{Notas:}

1. Submetida e aprovada pelo Comitê de Ética em Pesquisa (CEP) da UERN, em 2020, cujo número do parecer é 3.838.841.

2. Disponível em: https://www.uern.br/controledepaginas/poseduc-disserta\%C3\%A7oes2018/arquivos/6091brena_kecia_andrade_de_oliveira.pdf.

3. Referem-se a condutas, as formas de estabelecer relações com os outros e também a autorreflexão sobre o desempenho profissional (BALL, 2005), considerando que as políticas curriculares influenciam na subjetividade docente por meio dos sentidos educacionais defendidos e das demandas atribuídas aos sujeitos escolares, produzindo novas sensibilidades, valores e novas formas de ser e estar.

4. A exemplo de "Recriando rotas", cujo objetivo é fortalecer a leitura e a escrita dos alunos, e "Corrigindo rotas", que busca oferecer reforço de matemática

5. Coordenadoria Regional de Desenvolvimento da Educação (CREDE 8) e Superintendência das Escolas Estaduais de Fortaleza, respectivamente.

6. "É uma das ações que integram a Política Nacional de Formação de Professores e tem por objetivo induzir o aperfeiçoamento da formação prática nos cursos de licenciatura, promovendo a imersão do licenciando na escola de educação básica, a partir da segunda metade de seu curso" (CAPES, 2018, s/p).

7. Disponível em: http://sociologia.ihl.unilab.edu.br/index.php/sem-categoria/1a-semana-de-sociologia- nasescolas-do-macico-de-baturite/ Acesso em: 17 maio 2020.

8. Disponível em: http://sociologia.ihl.unilab.edu.br/index.php/sem-categoria/2a-semana-de-sociologia- naunilab/ Acesso em: 17 maio 2020.

\section{Referências}

BALL, Stephen J. Profissionalismo, gerencialismo e performatividade. Cadernos de pesquisa, v. 35, n. 126, p. 539-564, 2005.

BALL, Stephen J. Reformar escolas/reformar professores e $\quad$ os terrores da 
performatividade. Revista Portuguesa de educação, v. 15, n. 2, p. 3-23, 2002.

BALL, Stephen J. Diretrizes políticas globais e relações políticas locais em educação. Currículo sem fronteiras, v. 1, n. 2, p. 99-116, 2001.

BALL, Stephen J. Educação global S.A.: novas redes políticas e o imaginário neoliberal. Ponta Grossa: Editora da UEPG, 2014.

BALL, S. J.; MAGUIRE, M.; BRAUN, A. Como as escolas fazem as políticas: atuação em escolas secundárias. Tradução de Janete Bridon. Ponta Grossa: UEPG, 2016.

BRASIL. Ministério da Educação. Base Nacional Comum Curricular. Brasília: MEC. Versão entregueao CNE em 03 de abril de 2018. Disponível em: http://basenacionalcomum.mec.gov.br/images/BNCC_EI_EF_110518_versaofinal_site. pdf. Acesso em: 04 abr. 2019.

BRASIL. Casa Civil. Lei n. 13.415, de 16 de fevereiro de 2017. (Conversão da medida provisória de n. 746, de 2016). Brasília, 2017. Disponível em: http://www.planalto.gov.br/ccivil_03/_ato20152018/2017/lei/113415.htm. Acesso em: 28 mar. 2017.

CEARÁ. Grupo Escolar. Projeto político-pedagógico. Cidade: [Preservada para não quebrar anonimato], 2020.

CEARÁ. Escola Reunida. Projeto político-pedagógico. Cidade: [Preservada para não quebrar anonimato], 2014.

GASTALDO, Denise. Prefácio. In: MEYER, Dagmar Estermann; PARAÍSO, Marlucy Alves. Metodologias de pesquisas pós-críticas em educação. Belo Horizonte: Mazza, 2013. p. 312.

GEWIRTZ, Sharon; BALL, Stephen. Do modelo de gestão do "Bem-Estar Social" ao "novo gerencialismo": mudanças discursivas sobre gestão escolar no mercado educacional. In: BALL, Stephen; MAINARDES, Jefferson. Políticas educacionais: questões e dilemas. São Paulo: Cortez, 2011. p. 193-221.

INSTITUTO UNIBANCO. Circuito de gestão. Disponível em: https://iuportalhmg.azurewebsites.net/metodo/ Acesso em: 10 jun. 2020.

LOCKMANN, Kamila. Ferramentas, procedimentos e posicionamentos: uma tríade que constitui os caminhos investigativos. In: VEIGA-NETO, A. et al. (org.). Pesquisas em educação: experimentando modos investigativos. Rio Grande: FURG, 2013. p. 180.

LOPES, Alice Casimiro; MACEDO, Elizabeth. Teorias de currículo. São Paulo: Cortez, 2011.

LOPES, Alice Casimiro. Teorias pós-críticas, política e currículo. Educação, sociedade \& culturas, v. 39, n. 39, p. 7-23, 2013.

LOPES, Alice Casimiro. A Teoria da Atuação de Stephen Ball: e se a noção de discurso fosse outra? Archivos Analíticos de Políticas Educativas, Arizona, v. 24, n. 25, 2016.

MACEDO, Elizabeth. Base Nacional Curricular Comum: novas formas de sociabilidade produzindo sentidos para educação. Revista E-curriculum, v. 12, n. 3, p. 1530-1555, 2014.

MAINARDES, Jefferson. Entrevista com o Professor Stephen J. Ball. Olhares: Revista do Departamento de Educação da Unifesp, v. 3, n. 2, p. 161-171, 2015.

OLIVEIRA, Brena Kécia Andrade; OLIVEIRA, Meyre-Ester Barbosa; RÖWER, Joana Elisa. A contingência da disciplina de sociologia em cenário de reformas. Revista Eletrônica Científica Ensino Interdisciplinar, v. 6, n. 17, 2020.

OLIVEIRA, M. E. Podem as escolas produzir política? In: SANTOS, J.; OLIVEIRA, M.; PAZ, S. (org.). Reinvenções do currículo: sentidos e reconfigurações no contexto escolar. Fortaleza: UFC, 2016. p. 319.

RÖWER, Joana Elisa; OLIVEIRA, Brena Kécia Andrade; FREIRE, Newton Malveira. Currículo em disputa: as componentes de Sociologia e NTPPS na escola de Ensino Médio. Latitude, v. 14, n. Esp., p. 257-285, 2021. 
SANTOS, Jean; OLIVEIRA, Márcia. Tensões permanentes na reforma do ensino médio. In: LOPES, Alice; OLIVEIRA, Márcia. Políticas de currículo: pesquisas e articulações discursivas. Curitiba: CRV, 2017. p. 169-188.

SANTOS, Jean; SILVA, Maria. Políticas de currículo na escola: atores e sentidos construídos em contexto. In: SANTOS, Jean; MARTINS, Elcimar. Ensino médio: políticas educacionais, diversidades, contextos locais. Fortaleza: Eduece, 2017. p. 17- 38.

VENCO, Selma. A precariedade do trabalho docente no Brasil. Disponível em: https://www.youtube.com/watch?v=MQCFwu_NAXk. Acesso em: 16 jul. 2020.

\section{Correspondência}

Brena Kécia Andrade de Oliveira: Bacharela em Humanidades e Licenciada em Sociologia pela Universidade da Integração Internacional da Lusofonia Afro-Brasileira e Mestra em Educação pela Universidade do Estado do Rio Grande do Norte (UERN).

E-mail: brenakeciaa@gmail.com

Autor (nome completo): Meyre-Ester Barbosa de Oliveira: Professora Adjunta da Universidade do Estado do Rio Grande do Norte (UERN), vinculada ao curso de Pedagogia da Faculdade de Educação, Mossoró/RN. Doutora em Educação pelo Programa de Pós-Graduação em Educação (PROPED) da Universidade do Estado do Rio de Janeiro (UERJ). Líder do Grupo de Pesquisa Currículo e Ensino (GEPCE). Tem participado de pesquisas e publicado artigos e capítulos de livros com foco em formação de professores e políticas curriculares.

E-mail: meyreoliveira@uern.br

Texto publicado em Currículo sem Fronteiras com autorização dos autores. 